\title{
GOVERNANÇA DEMOCRÁTICA: UMA GENEALOGIA ${ }^{1}$
}

\begin{abstract}
Mark Bevir
RESUMO

Este artigo trata de problemas na teoria e na prática democráticas. No século XX novas teorias econômicas e sociológicas da racionalidade dominaram a Ciência Social, enfraquecendo os antigos ideais da democracia representativa. Por algum tempo, o paradigma burocrático pareceu oferecer uma solução, mas na década de 1980 a burocracia era criticada como ineficiente e irresponsável. Como se poderia lidar com os problemas resultantes da governança democrática? Atores políticos responderam a essa pergunta aferrando-se ao antigo ideal da democracia representativa apoiada por formas de conhecimento técnico baseadas nas novas teorias da racionalidade. Assim, uma nova governança de mercados e redes difundiu-se pelo mundo. Com isso, os governos representativos ainda lutam para dirigir o processo politico, ao mesmo tempo que um conhecimento técnico ilusório entulha a participação democrática. A democracia contemporânea sofre tanto com os limites borrados da accountability quanto com a legitimidade declinante. $O$ artigo conclui sugerindo que a renovação democrática pode depender de estilos mais interpretativos de conhecimento técnico, de formas dialógicas de elaboração de políticas públicas e de diversas vias de participação pública.
\end{abstract}

PALAVRAS-CHAVE: governança; democracia; accountability; modernismo; idéias políticas; políticas públicas.

\section{INTRODUÇÃO}

Quando a palavra "governança" refere-se à organização e à ação públicas, ela captura uma das maiores tendências dos tempos atuais. Cientistas sociais, especialmente aqueles que pesquisam a administração pública e o governo local, acreditam que a organização e a ação públicas moveram-se da hierarquia e da burocracia para os mercados e as redes. Dúvidas podem permanecer a respeito de qualquer tentativa de exagerar a mudança: seguramente as hierarquias burocráticas mantêm-se espalhadas e são, sem dúvida, as formas mais comuns de governo. Questões podem manter-se a respeito da natureza da mudança: os governos tornaram-se menos capazes de definir seus rumos ou meramente alteraram as formas de fazerem-no? Ainda assim, a despeito dessas dúvidas e questões, há um amplo consenso de que a "governança" captura uma alteração

1 O presente artigo é a tradução de "Democratic Governance: A Genealogy", apresentado no X Congresso Anual da Western Political Science Association, realizado de 31 de março a 3 de abril de 2010, em San Antonio (Estados Unidos). Tradução de Gustavo Biscaia de Lacerda e revisão da tradução de Ricardo V. Silva.

Recebido em 15 de novembro de 2010 Aprovado em 30 de novembro de 2010. na teoria e na prática em direção a mercados e a redes.

Este ensaio baseia-se em meu livro Democratic Governance (BEVIR, 2010) e oferece uma genealogia da governança, assim como explora suas implicações para a democracia. Meus argumentos podem ser rapidamente apresentados como segue:

- a governança surgiu e espalhou-se como uma conseqüência de novas teorias modernistas e das reformas do setor público que foram inspiradas por tais teorias;

- os atores políticos respondem aos desafios da governança acrescentando às instituições representativas ainda mais conhecimento técnico modernista.

\section{UMA GENEALOGIA DA GOVERNANÇA}

No final do século XIX, a Ciência Política era dominada por um historicismo desenvolvimentista que inspirou grandes narrativas centradas na nação, no Estado e na liberdade. Esse tipo de historicismo apelava para narrativas que situavam eventos e instituições em uma ampla ordem de progressiva continuidade; exemplos dele incluem

Rev. Sociol. Polít., Curitiba, v. 19, n. 39, p. 103-114, jun. 2011 
a história whig $^{2}$, a filosofia idealista e a teorização evolucionista. O traço mais significativo da Ciência Social do século XX foi, em claro contraste, o surgimento de modos modernistas de conhecimento que atomizam o fluxo da realidade. A Tabela 1 oferece um resumo dessas concepções.

TABELA 1 - SURGIMENTO E VARIEDADES DO MODERNISMO

\begin{tabular}{|c|c|c|c|}
\hline \multirow[t]{2}{*}{ ÂMBITO } & \multirow{2}{*}{$\begin{array}{c}\text { HISTORICISMO } \\
\text { DESENVOLVIMENTISTA }\end{array}$} & \multicolumn{2}{|c|}{ MODERNISMO } \\
\hline & & GOVERNO & NOVA GOVERNANÇA \\
\hline $\begin{array}{l}\text { Conceito de } \\
\text { racionalidade }\end{array}$ & Civilizacional & $\begin{array}{l}\text { Econômica e } \\
\text { sociológica }\end{array}$ & $\begin{array}{c}\text { Novas teorias da governança- } \\
\text { escolha racional e neo- } \\
\text { institucionalismo }\end{array}$ \\
\hline $\begin{array}{l}\text { Formação do } \\
\text { Estado }\end{array}$ & $\begin{array}{l}\text { Estado-nação e/ou Estado } \\
\text { imperial }\end{array}$ & $\begin{array}{c}\text { Estado corporativo e/ou } \\
\text { Estado de Bem-Estar } \\
\text { Social }\end{array}$ & $\begin{array}{l}\text { Estado neoliberal e/ou Estado em } \\
\text { rede }\end{array}$ \\
\hline Setor público & ServiçoPúblico & Burocracia & $\begin{array}{l}\text { Novos mundos da governança- } \\
\text { mercados e redes }\end{array}$ \\
\hline $\begin{array}{l}\text { Modalidade de } \\
\text { accountability }\end{array}$ & Governo responsável & $\begin{array}{l}\text { Accountabilityvia } \\
\text { procedimentos }\end{array}$ & Accountability via desempenho \\
\hline
\end{tabular}

FONTE: o autor.

A ruptura modernista com o historicismo desenvolvimentista teve aspectos formais e substantivos. Em termos formais, os modernistas passaram de narrativas históricas para modelos formais, correlações e classificações que perpassam o tempo e o espaço. Eles explicam os resultados por meio de referências a tipos psicológicos, exigências funcionais dos sistemas, uma racionalidade humana geral e mecanismos e processos anistóricos. Em termos substantivos, o modernismo incorporou novos tópicos emergentes, incluindo partidos políticos, grupos de interesse e redes políticas. Os aspectos substantivos e formais do modernismo freqüentemente reforçam um ao outro: as novas técnicas tornaram mais fácil estudar alguns dos novos tópicos e os novos tópicos pareciam requerer novas técnicas para obter e organizar os dados.

A Ciência Social contemporânea é dominada por duas variedades de modernismo. Ambas constrastam com o historicismo desenvolvimentista, mas cada uma contempla diferentes conceitos formais e anistóricos da racionalidade associada a diferentes formas de explicação e, assim, a diferentes análises da governança e da democracia. Por um lado, o conceito econômico da racionalidade privilegia a maximização da utilida-

\footnotetext{
2 A "história whig" refere-se à historiografia desenvolvida por pensadores simpáticos ao partido Whig, que eram os liberais e os democratas britânicos, opostos ao partido Tory, conservador (nota do tradutor).
}

de; ela surge com a teoria econômica neoclássica e difunde-se com a teoria da escolha racional. Por outro lado, o conceito sociológico de racionalidade privilegia a adequabilidade relativamente às normas sociais; ele surgiu com o funcionalismo e difundiu-se com a teoria das redes e com o comunitarismo.

O conceito econômico de racionalidade encontrado na teoria neoclássica tem uma história específica. Ao longo do século XIX, os economistas fundiram as análises avançadas por Adam Smith com temas orgânicos e históricos. A economia neoclássica estabeleceu sua predominância somente quando o historicismo desenvolvimentista cedeu espaço para o modernismo. Mesmo então ela não obliterou outras tradições; as abordagens histórica e institucional da economia continuaram a prosperar, especialmente no continente europeu, onde os economistas permaneceram divididos a respeito da teoria da utilidade até o final dos anos 1930. No entanto, a difusão do modernismo viu as narrativas diacrônicas do desenvolvimento de economias, estados e civilizações ceder espaço para os modelos sincrônicos e as correlações estatísticas.

A economia neoclássica incorpora um conceito de racionalidade adequado à ênfase modernista na atomização, na dedução e nas análises sincrônicas. A racionalidade econômica é uma propriedade de decisões e ações individuais; ela não se vincula a normas, práticas ou sociedades, exceto na medida em que estas sejam julgadas 
adequados meios efetivos ou inefetivos para agregar as escolhas individuais. Além disso, essa racionalidade é postulada como um axioma sobre o qual se pode elaborar modelos dedutivos; ela não é estruturada como um princípio com o qual se possa interpretar fatos descobertos por meio de pesquisa indutiva e empírica. Finalmente, os modelos derivados dos axiomas da racionalidade econômica são aplicados a padrões gerais, independentemente de tempo e espaço; eles não rastreiam as evoluções particulares de indivíduos, práticas ou sociedades. A perspectiva modernista do conhecimento prepara a cena para o conceito econômico de racionalidade, mas é com a maximização da utilidade que o conceito adquire seu conteúdo. Na economia neoclássica, os indivíduos agem de modo a maximizar sua utilidade pessoal, em que a utilidade é definida como uma medida da satisfação ou da felicidade obtida de um bem consumível ou de outro resultado.

As mais proeminentes alternativas para o conceito econômico de racionalidade são os conceitos sociológicos, que substituem a instrumentalidade pela adequabilidade. A racionalidade sociológica trata do agir de acordo com normas sociais apropriadas a fim de desempenhar papéis estabelecidos em sistemas, processos, instituições ou práticas. Alguns sociólogos, incluindo Emile Durkheim e Pierre Bourdieu, argumentaram que mesmo os modernos indivíduos são melhor concebidos não como atores instrumentais mas como seguidores de normais e papéis sociais; outros sociólogos, incluindo Max Weber e Herbert Marcuse, expressam temores a respeito da difusão de normas egoístas, aquisitivas e instrumentais nas modernas sociedades. Assim, os dois ramos da Sociologia modernista podem andar juntos em amplas condenações da modernidade, do capitalismo ou do consumismo, vistos como difusores de normas egoístas e instrumentais que arruínam formas antigas de solidariedade e comunidade.

É digno de nota que essas tradições sociológicas, com seus conceitos alternativos de racionalidade, datam, assim como a economia neoclássica, da ampla passagem intelectual do historicismo desenvolvimentista para o modernismo, com sua ênfase em análises sincrônicas. Os aspectos comuns dos conceitos econômico e sociológico de racionalidade são tão importantes quanto suas diferenças. Os economistas e os so- ciólogos modernistas compartimentalizam aspectos da vida social a fim de lidar com os fatos e explicá-los; procuram compreender o particular não ao localizá-lo em uma narrativa temporal mas ao reduzi-lo a generalizações formais de nível intermediário ou universal que supostamente perpassam o tempo e o espaço. Os sociólogos, assim como os economistas, podem esboçar modelos dedutivos, mas também eles rejeitam narrativas, preferindo classificações formais, correlações, funções, sistemas e tipos ideais. Embora possamos observar temas funcionalistas no século XIX, essas formas sociológicas de explicação floresceram somente com o surgimento do modernismo; foram Durkheim e Bronislaw Malinowski, não Augusto Comte e Herbert Spencer, que distinguiram as explicações funcionais que se referem ao papel sincrônico de um objeto em um sistema ou ordem social (um tipo de explicação que eles consideravam científica) tanto da questão psicológica da motivação quanto da questão histórica das origens.

A passagem do historicismo desenvolvimentista para o modernismo alterou o conceito e a natureza do Estado. Como os modernistas rejeitaram as narrativas históricas, eles também desafiaram o conceito do Estado como surgindo de uma nação juntamente com língua, cultura e passado comuns. Em vez disso, os modernistas voltaram-se para padrões formais, regularidades ou modelos de ação e instituições ao longo do espaço e do tempo. Novamente: quando os modernistas passaram de um foco substantivo no Estado para tópicos como partidos políticos, grupos de interesse e redes políticas, essas instituições subestatais foram estudadas em termos de leis ou regularidades derivadas, por exemplo, de suas funções em sistemas abstratos. Mesmo quando os modernistas permaneceram estudando o Estado, eles cada vez mais o representaram como fragmentado em interesses facciosos associados a diferentes classes ou partidos.

O modernismo desafiou a idéia de que a democracia representativa era uma forma de eleger e de avaliar os políticos, que por sua vez poderiam agir de acordo com o bem comum de uma nação. Desse modo, a democracia representativa estava em perigo de perder muito de sua legitimidade. Ainda assim, as formas modernistas de conhecimento revelaram novos modos de elaborar e legitimar as políticas públicas nas democracias 
representativas; em particular, a Ciência Social modernista inspirou uma nova crença na especialização formal. Os representantes eleitos não precisam mais expressar um caráter nacional e o bem comum; eles podem definir objetivos políticos e verificar a atividade de especialistas. Cientistas sociais, profissionais e servidores públicos generalistas poderiam usar seus conhecimentos técnicos para elaborar políticas racionais e científicas de acordo com esses objetivos. A Ciência Social modernista ajudou assim a criar as condições para o Estado administrativo.

Uma justificativa importante para a criação de uma burocracia crescentemente insulada e centralizada foi a necessidade de lidar com abusos e irracionalidades nos processos democráticos. Cientistas sociais modernistas, como Mosei Ostrogrorski, Graham Wallas e W. F. Willoughby, escreveram a respeito do facciosismo, da doutrinação política e das extravagâncias financeiras a que os governos democráticos estão predispostos. Muitos acreditavam que uma burocracia insulada e centralizada poderia tanto preservar a democracia quanto remover seus piores aspectos - a instabilidade, a irracionalidade e o sectarismo - das atividades diárias do governo. O corporativismo e o Estado de Bem-Estar Social surgiram em parte como arranjos burocráticos para superar o facciosismo e a irracionalidade. Com o corporativismo, a burocracia procurou organizar os interesses e intermediar suas disputas. O Estado corporativista conferiu às associações particulares um status privilegiado como representantes dos grupos sociais e econômicos. As associações privilegiadas eram envolvidas na formulação de políticas públicas e elas retribuíam ajudando a assegurar a implementação dessas políticas. A burocracia também procurou cidadãos individuais, assumindo maiores responsabilidades pelo seu bem-estar. O Estado de Bem-Estar Social assumiu o controle dos interesses individuais com educação, pensões e seguro-desemprego; ele desenvolveu políticas não somente para redistribuir recursos mas também para assegurar que esses recursos seriam usados racionalmente para atingir as necessidades dos cidadãos.

A governança surgiu em grande parte devido a uma crise no Estado modernista. As supersimplificações abundarão em qualquer tentativa de diferenciar a pletora de idéias que alimentam as narrativas a respeito da crise do Estado no final do século XX; no entanto, uma forma de aproximação dessas narrativas é percebê-las como incorporando diferentes análises modernistas. Algumas narrativas da crise do Estado desafiaram a burocracia, o corporativismo e o Estado de BemEstar Social em termos do conceito econômico de racionalidade. Concepções neoclássicas sobre o nível "micro" informam, por exemplo, narrativas que tentaram apresentar as crises fiscais como sendo uma patologia constituída no interior do Estado de Bem-Estar Social. Essas narrativas procediam como se segue. Os cidadãos, sendo atores racionais, tentam maximizar seus interesses de curto prazo, privilegiando as políticas de bemestar que os beneficiam como indivíduos, em vez dos efeitos de longo prazo, cumulativos e compartilhados resultantes do aumento dos gastos estatais. De maneira semelhante, os políticos, sendo atores racionais, tentam maximizar seus interesses eleitorais de curto prazo, promovendo políticas que obterão os votos dos cidadãos racionais, em vez de perseguir a responsabilidade fiscal. Considerações políticas estreitas assim prevalecem sobre imperativos econômicos. Grupos de eleitores demandam mais e mais benefícios de bem-estar e políticos constantemente aprovam legislação de bem-estar em benefício desses eleitores. Essas narrativas de um Estado sobrecarregado e da crise do Estado apontam para uma clara solução - a austeridade fiscal, o controle monetário e uma redução do tamanho do Estado.

Outras narrativas da crise do Estado elaboraram análises mais sociológicas das mudanças no mundo; elas implicam que o Estado tinha que mudar em resposta a pressões internacionais e domésticas. Internacionalmente, a crescente mobilidade do capital tornara mais difícil para os estados dirigirem a atividade econômica. O Estado não poderia mais atuar sozinho, tendo, em vez disso, que tratar da coordenação e da regulação através das fronteiras. As indústrias que agiam no âmbito do Estado nacional tornaram-se crescentemente transnacionais em suas atividades. Os crescentes número e proeminência das corporações transnacionais originaram problemas de coordenação e questões de jurisdição. Havia um vazio entre as atividades nacionais das estruturas regulatórias e a economia crescentemente internacional. Domesticamente, o Estado confrontou-se com as crescentes demandas de seus cidadãos; tais demandas surgiram do descontentamento popular com a maneira como o Estado li- 
dava com a economia e com sua aparente irresponsabilidade: muitos estados foram sobrecarregados com grandes dívidas; a globalização provocou ansiedades a respeito da competitividade e dos salários; partes do público preocuparam-se com que o Estado tivesse perdido o controle. Da mesma forma, atores estatais freqüentemente consideraram que estavam sujeitos a variadas e mesmo contraditórias demandas do público. Os eleitores demandavam melhores serviços e menores impostos; eles queriam um Estado mais efetivo mas também mais transparente e responsabilizável; queriam líderes decididos e ainda mais participação popular.

A nova governança consiste nas teorias e nas reformas interconectadas por meio das quais os povos conceberam a crise do Estado e responderam a ela. Essas teorias e reformas rejeitaram o conhecimento técnico associado ao Estado posterior à II Guerra Mundial. Entretanto, em vez de desafiar a idéia de aplicar o conhecimento técnico modernista à vida social, os atores políticos viraram-se para modos modernistas alternativos de conhecimento para apoiar novas formas de conhecimento técnico. A governança surgiu então em duas ondas analiticamente distintas da reforma do setor público. A primeira consistiu nas reformas associadas ao conceito econômico de racionalidade - o neoliberalismo, a Nova Administração Pública [New Public Management ${ }^{3}$ ] e a terceirização. A segunda consistiu em reformas associadas a conceitos sociológicos de racionalidade - a Terceira $\mathrm{Via}^{4}$, a governança joined-up 5 e redes e parcerias.

3 O New Public Management foi uma forma de pensar prevalecente nos Estados Unidos entre as décadas de 1980 e 2000 que afirmava serem necessárias reformas em direção ao mercado para o Estado melhorar seu desempenho; tais reformas incluíam a diminuição da estrutura estatal, assim como a concepção de que os cidadãos são consumidores (N. T.).

4 A Terceira Via foi um movimento político teorizado pelo sociólogo inglês Anthony Giddens em apoio às reformas liberalizantes do Primeiro-Ministro trabalhista Tony Blair (1997-2007). De acordo com eles, o Estado deveria diminuir sua atuação direta na economia e dar mais espaço para a iniciativa privada, mas sem abrir mão de seus mecanismos de controle e direção sócio-econômica e de combate às desigualdades sociais (N. T.).

5 A expressão "joined-up" é de difícil tradução no presente contexto. O governo joined-up é uma proposta para que diferentes setores de um governo trabalhem em conjunto,
Uma primeira onda de reformas baseou-se na insatisfação pública com a burocracia e também no neoliberalismo e na teoria da escolha racional, ambos os quais explicaram e legitimaram essa insatisfação. Os neoliberais comparam o modo de organização estatal - hierárquico, de cima para baixo - com a estrutura descentralizada e competitiva do mercado. Eles argumentam que o mercado é superior ao Estado e concluem que quando possível os mercados ou quase-mercados devem substituir a burocracia. A busca por eficiência conduziu-os a propor que o Estado transferisse organizações e atividades para o setor privado: as organizações poderiam ser transferidas por meio da privatização, isto é, da transferência de bens do Estado para o setor privado por meio da abertura de capital ou da cessão do controle acionário; as atividades poderiam ser transferidas por meio da terceirização, isto é, o Estado pagaria a uma organização do setor privado para que esta realizasse tarefas em seu benefício.

Muitos neoliberais combinam sua fé nos mercados com uma fé em que a disciplina do mercado deveria de alguma forma validar as práticas gerenciais do setor privado; assim, redefinem os servidores públicos como gerentes ou provedores de serviços e os cidadãos como consumidores ou usuários de serviços. Mais especificamente, as reformas neoliberais da administração pública freqüentemente refletem análises formais. Os economistas neoliberais primeiramente desenvolveram a teoria de diretor-agente [principal-agent theory] para analisar o problema da discricionaridade delegada no setor privado, argumentando que delegar a tomada de decisões dos diretores (acionistas) para os agentes (gerentes) é arriscado, pois os agentes podem agir em favor de seus interesses particulares. Esses economistas propuseram minimizar esse risco com o uso de incentivos e de mecanismos de mercado, a fim de alinhar os interesses dos agentes com os dos diretores. No setor público, os diretores são os eleitores e seus representantes eleitos, ao passo que os agentes são os servidores públicos. Para os teóricos da escolha racional, portanto, assim como o

delimitando metas e objetivos transversais a eles, buscando a coordenação e a sinergia dos esforços e dos resultados. Evidentemente, ele opõe-se às ações específicas - e por vezes contrapostas - de cada um dos setores envolvidos. O governo joined-up foi proposto pelo Primeiro-Ministro inglês Tony Blair ano longo dos anos 1990 (N. T.). 
problema básico das corporações do setor privado parecia ser garantir que os gerentes atuem em benefício dos acionistas, o problema básico da administração pública parecer ser assegurar que os servidores públicos trabalhem em benefício dos cidadãos. Os neoliberais estenderam ao setor público os incentivos e os mecanismos de mercado que os economistas determinaram para alinhar os interesses dos agentes aos dos diretores.

As narrativas popular e neoliberal combinaramse com análises mais formais para produzir uma mudança de paradigma no modernismo. $\mathrm{O}$ novo paradigma denunciava a burocracia e os servidores públicos e defendia os mercados e os empresários. Ele afastou-se do que era agora ridicularizado como "elefante branco" [big government], burocracia inchada e soluções homogeneizantes; dirigiu-se para um setor privado que era agora celebrado como competitivo, eficiente e flexível. Essa mudança de paradigma é também relativa a definições institucionais de bom governo, que enfatiza divisões evidentes de responsabilidades, em um contexto de relações hierárquicas, em direção a novas definições de processos eficientes definidos em termos de prestação de serviços e resultados com uma ênfase correlata na transparência, na acessibilidade dos usuários [userfriendliness] e nas estruturas de incentivo.

Quando os cientistas sociais inspirados pelas teorias sociológicas da racionalidade estudaram as reformas neoliberais do setor público, com freqüência foram altamente críticos, argumentando que as reformas incrementaram problemas de coordenação e de orientação; por seu turno, promoveram redes e o governo joined-up. Os defensores das redes distinguem-nas das hierarquias e dos mercados. Os antigos institucionalistas acreditavam que as hierarquias tornam mais fácil lidar com muitas atividades ao dividi-las em tarefas menores, cada qual pode ser então realizada por uma unidade especializada. Os neoinstitucionalistas argumentam que essa abordagem de solução de problemas não se adapta mais ao mundo contemporâneo. Hoje os formuladores de políticas crescentemente se confrontam com "problemas capciosos" que não são acessíveis pela divisão e pela especialização: solucionar esses problemas requer as redes.

O conceito de "problemas capciosos" surge como parte de uma Ciência Social de escopo intermediário e amorfa associada ao instituciona- lismo, à teoria das organizações e ao funcionalismo. Os governos social-democráticos então o assumiram e adotaram-no para contraporem-se às idéias e políticas neoliberais. Os problemas capciosos são geralmente definidos em termos como estes: um problema de natureza mais ou menos única; a falta de qualquer formulação definitiva de tal problema; a existência de múltiplas explicações para ele; a ausência de um teste para decidir o valor de qualquer resposta para ele; todas as respostas são melhores ou piores que "verdadeiro" ou "falso"; cada uma tem importantes conseqüências de modo que não há possibilidade de aprender a lidar com ele por tentativa e erro. Tipicamente essas características implicam fortemente que os problemas capciosos são interrelacionados; por exemplo, um problema capcioso particular poderia ser explicado em termos de suas relações com outros, ou qualquer resposta para ele poderia influenciar outros. Exemplos clássicos desses problemas incluem temas urgentes da governança, como segurança, meio ambiente e decadência urbana.

Assim, muitos institucionalistas aceitam os argumentos neoliberais a respeito da natureza inflexível e irresponsiva das hierarquias, mas, em vez de promoverem os mercados, eles apelam para as redes como uma alternativa adequadamente flexível e responsiva baseada no reconhecimento de que os atores sociais operam em relações estruturadas. Eles argumentam que a eficiência e a eficácia derivam de relações estáveis caracterizadas pela confiança, pela participação social e pelas associações voluntárias. Em sua perspectiva, embora as hierarquias possam fornecer um contexto para a confiança e a estabilidade, o seu tempo já passou, pois não se ajustam à nova economia global baseada no conhecimento. Esse novo mundo crescentemente lança problemas capciosos que requerem redes e governança joined-up. Assim, foi um neo-institucionalismo, com seu conceito sociológico de racionalidade, que inspirou uma segunda onda de reformas, incluindo muitas políticas do New Labour ${ }^{6}$, da agenda aus-

\footnotetext{
6 O New Labour consistiu nas reformas políticas, econômicas e sociais conduzidas pelo Partido Trabalhista inglês (Labour Party) sob a liderança de Tony Blair ao longo dos anos 1990, que combinava, como indicado anteriormente, a proteção social com reformas voltadas para o mercado (N. T.).
} 
traliana do whole-of-government ${ }^{7}$, das tentativas internacionais de lidar com os estados falidos e da política de segurança estadunidense posterior aos atentados de 2001.

\section{E A RESPEITO DA DEMOCRACIA?}

Tenha ou não o surgimento da governança conduzido a serviços públicos mais eficientes e responsivos, ela certamente sugere problemas de transparência e de legitimidade. Os atores do setor público não são democraticamente eleitos e é raro que eles sejam diretamente responsabilizáveis perante os representantes eleitos. Assim, um aumento de sua importância no setor público origina questões sobre a accountability.

Alguns dos temas que confrontam a governança democrática recuam no tempo até o surgimento da Ciência Social modernista. O co- lapso do historicismo desenvolvimentista enfraqueceu inúmeros dos pressupostos que havia muito acompanhavam a democracia representativa. Não se poderia mais ver o Estado como a expressão do bem comum de um povo ou de uma nação; não se poderia mais assumir que políticos e servidores responsáveis agiriam de acordo com o bem comum. O problema de assegurar que representantes fossem responsáveis cedeu lugar para o de torná-los responsivos. Ainda assim, mesmo que o modernismo tenha revelado fraturas na democracia representativa, ele escondeu-as graças a apelos a um conhecimento técnico aparentemente neutro. A nova governança fez algo muito parecido. A principal mudança foi o contexto do conhecimento técnico e o pano de fundo de hoje é uma mistura de teoria da escolha racional com o neoinstitucionalismo. A Tabela 2 sumaria esse padrão.

TABELA 2 -ADMIRÁVEL NOVADEMOCRACIA

\begin{tabular}{|l|c|c|}
\hline \multicolumn{1}{|c|}{ ÂMBITO } & ESCOLHA RACIONAL & INSTITUCIONALISMO \\
\hline Base da democracia & Representação & Representação \\
Bem comum & $\begin{array}{c}\text { Agregado de interesses } \\
\text { individuais }\end{array}$ & Novo serviço público \\
Cidadania & Consumista & Comunitária \\
Repensando a democracia & Instituições não-majoritárias & Inclusão social \\
Repensando aaccountability & Accountabilityde desempenho & Accountabilityhorizontal ou de rede \\
\hline
\end{tabular}

Para os historicistas desenvolvimentistas, a democracia representativa era uma aquisição histórica. A sociedade civil (ou o estágio da civilização) que era necessário para manter a democracia representativa servia para promover ideais morais e comportamentos como os elaborados para o governo responsável. A responsabilidade referia-se tanto ao caráter dos políticos e servidores quando ao seu relacionamento com o público. Os políticos e servidores tinham o dever de responder às demandas, aos desejos e às necessidades do povo. Agir responsavelmente era agir de

\footnotetext{
7 A política australiana do whole-of-government, que traduzido literalmente significaria "[de] todo o governo", é a versão local das políticas que lidam com problemas cuja solução exige tratamentos colegiados da parte dos órgãos públicos. Em outras palavras, é o mesmo princípio de governança do que na Inglaterra, como vimos, é denominado "governo joined-up" e nos Estados Unidos, de governo em rede (networked government) (N. T.).
}

modo a promover o bem comum mais que procurar vantagens pessoais; era perseguir interesses nacionais e, assim, superar facciosismos mesquinhos. Palavras e conceitos próximos a "responsabilidade" eram igualmente proeminentes em outras línguas européias, como verantwoordelijkheid (neerlandês), responsabilité (francês), verantwortlichkeit (alemão), responsabilità (italiano) e responsabilidad (espanhol). Em marcado contraste, "accountability" raramente apareceu em dicionários ou enciclopédias antes do século XX.

O conceito de accountability surgiu ao longo do modernismo. Por um lado, o modernismo estava associado a uma perda de fé nos princípios que haviam sustentado a crença no progresso das nações em direção ao Estado organizado [statehood], à liberdade e ao governo representativo e responsável. Os modernistas crescentemente descreveram a própria nação como fragmentada e assim a democracia pareceu menos 
uma forma de expressar o bem comum e mais uma disputa entre facções ou classes. Por outro lado, o modernismo deu origem a novas formas de Ciências Sociais aparentemente neutras. A Ciência Social desenvolveu-se para fornecer um conhecimento técnico neutro que poderia guiar a formulação de políticas; ela poderia mostrar-nos quais políticas poderiam produzir melhor quaisquer resultados ou valores que nossos representantes eleitos escolhessem. O modernismo, portanto, ajudou a manter a agora clássica distinção entre política e administração. O processo político gera valores ou decisões políticas, das quais o ministros são, dessa forma, os porta-vozes; os servidores públicos fornecem o conhecimento técnico politicamente neutro que formula e implementa as políticas que estão de acordo com esses valores ou decisões políticas. Nesse contexto, a responsabilidade, como concebida pelos historicistas desenvolvimentistas, torna-se menos relevante que a accountability dos servidores públicos em relação aos seus mestres políticos e a accountability dos políticos perante o eleitorado.

Uma íntima conexão entre a accountability e o conhecimento técnico-burocrático aparece no conteúdo da accountability. A teoria, quando não a prática, da accountability aplica-se muito mais firmemente aos servidores públicos que aos políticos. Os políticos são fiscalizáveis por meio das instituições da democracia representantiva; os legisladores são fiscalizáveis pelos eleitores que periodicamente decidem se devolvê-los-ão ou não aos parlamentos mais uma vez. O poder Executivo, especialmente os presidentes em sistemas políticos com forte separação dos poderes, também pode ser diretamente fiscalizável pelo eleitorado; de maneira alternativa, o poder Executivo, notadamente os primeiros-ministros e os gabinetes, podem ser fiscalizáveis por legislaturas que podem revogar a autoridade do governo. As teorias modernistas com freqüência sugerem que essas formas de accountability política são frágeis. Mesmo que os políticos e os governos possam perder eleições, com freqüência eles controlam o conhecimento, as agendas e os recursos de maneiras que os tornam mais poderosos que aqueles que procurariam forçá-los a prestar contas. Além disso, mesmo quando os políticos e os governos perdem eleições, com freqüência parece que suas quedas devem menos às suas condutas enquanto ocupavam os cargos que a tendências sociais e políticas mais amplas.
Os mecanismos para tornar os servidores públicos fiscalizáveis parecem mais firmes. A accountability administrativa ocorre em hierarquias burocráticas, que são constituídas para definir claramente uma divisão do trabalho especializada e funcional; elas especificam papéis claros para os indivíduos no processo de tomada de decisões, tornando assim possível identificar quem é responsável pelo quê. De modo típico, os servidores individuais são assim diretamente interpeláveis por seus superiores (e, em última análise, por seus mestres políticos) por suas ações. Some-se a isso que a accountability administrativa foi crescentemente complementada por uma variedade de ouvidores e outros meios judiciais para investigar-se a má administração e mesmo a corrupção.

Enquanto a accountability administrativa pareceu mais firme que a accountability política, ela foi comprovadamente um instrumento grosseiro. A accountability administrativa forneceu uma perspectiva teórica para dividir a culpa e procurar a reparação em casos de má administração. Mas os críticos da narrativa burocrática reclamaram que ela não fornece um meio de garantir e responder a diferentes níveis de desempenho. As novas teorias da governança, incluindo a teoria da escolha racional e a teoria das redes, ressaltaram preocupações que se sobrepuseram à questão do desempenho do setor público.

A teoria da escolha racional reformulou a accountability nos termos do problema diretoragente. $\mathrm{O}$ postulado dos atores racionais e autointeressados enfraqueceu a idéia de que servidores públicos poderiam geralmente ser confiáveis para agir desinteressadamente em benefício do bem comum. O problema não é verificar como eles comportam-se, mas criar um quadro em que seus interesses estejam alinhados aos daqueles em benefício de quem eles trabalham. Em vez de pensar em como tornar os agentes (políticos ou servidores públicos) fiscalizáveis por seus diretores (o eleitorado e os ministros, respectivamente), os teóricos da escolha racional sugeriram que a questão é como fazer os agentes atuarem de acordo com os interesses dos diretores; eles responderam essa questão largamente em termos da oferta de incentivos adequados para os agentes.

A teoria das organizações, e seu impacto nas teorias institucionalista e das redes, revelou um mundo em que a tomada de decisões era mais 
complexa que um processo envolvendo vários atores políticos em redes. Essa complexidade sugeriu que havia algo de ilusório, e mesmo injusto, no pressuposto de que as pessoas acima da hierarquia burocrática pudessem ser fiscalizáveis pelas decisões e ações de seus subordinados. Os papéis e as decisões administrativos e políticos raramente poderiam ser distinguidos uns dos outros; a responsabilidade ministerial tornou-se de maneira bastante óbvia um mito para ser levada a sério; a accountability procedimental parecia inapropriada, e também muito limitada, especialmente quando concebida como reativa a decisões que já tinham sido tomadas.

Mesmo que as novas teorias da governança tenham enfraquecido as formas de conhecimento técnico e de accountability associadas à narrativa burocrática, elas promoveram novas formas de conhecimento técnico modernista que apontam para novas abordagens da democracia e da accountability. Mesmo o conceito econômico da racionalidade inspirou os cientistas sociais a sugerir que poderíamos beneficiar-nos com menos democracia. Os neoliberais com freqüência contrastam a democracia - que permite aos cidadãos expressar sua preferência ao votar apenas uma vez a cada poucos anos e somente com um "sim" ou "não" a toda uma lista de políticos - com o mercado - que permite aos consumidores expressar suas preferências continuamente, com variadas intensidades e para itens individuais. Além disso, como vimos, os teóricos da escolha racional às vezes incomodam-se com o fato de que a democracia implica custos políticos de transação que conduzem a incessantes aumentos dos gastos públicos. Eles argumentam que o custo de vários itens dos gastos públicos é distribuído de maneira rarefeita para uma grande população, de modo que os eleitores individuais não têm motivos para oporem-se a ele; mas os benefícios são concentrados em uma pequena parcela da população, que assim cobra o aumento dos gastos. Eles defendem instituições não-majoritárias para proteger áreas políticas cruciais - como o setor bancário ou o orçamento público - da democracia.

Talvez valha dizer explicitamente que "nãomajoritário" é um pouco mais que um eufemismo para "não-democrático". Há razões conhecidas para querermos proteger uma série de bens, incluindo os direitos humanos, da tomada de decisões democrática. Ainda assim, os argumentos da escolha racional para as instituições não-majoritá- rias diferem dos argumentos em favor da proteção constitucional de direitos no fato de que eles baseiam-se não em valores morais mas em teorias da racionalidade alegadamente científicas. Tais teorias fiam-se em análises técnicas dos custos políticos de transação e de um vazio de credibilidade associadas a um problema de inconsistência temporal [time-inconsistency problem] para sugerir que a delegação de poderes para corpos não-majoritários reduz os custos políticos de transação em que os políticos incorrem porque lhes faltaria uma "tecnologia de compromisso" confiável.

Os cientistas sociais inspirados pelos conceitos mais sociológicos de racionalidade com freqüência ficam desconfortáveis com o crescimento de organizações não-majoritárias e não-democráticas. Muitos deles associam o papel crescente de tais organizações à crescente hostilidade pública à política e ao governo. Os institucionalistas respondem aos temas democráticos surgidos com os novos mundos da governança tentando expandir o conceito de legitimidade, de modo que este considere a efetividade, a accountability legal e a inclusão social. Às vezes eles vinculam a legitimidade à efetividade das organizações em fornecer bens públicos; às vezes eles atribuem a legitimidade a organizações que são criadas e reguladas por estados democráticos, não importando quão distantes e obscuras sejam as linhas da delegação: a legitimidade persiste porque as organizações independentes são legalmente fiscalizáveis e porque um governo democrático terá aprovado as leis relevantes. Finalmente, às vezes eles sugerem que a legitimidade das organizações e das decisões poderia residir em sua eqüidade e em sua inclusividade. Os proponentes dessa visão enfatizam a importância de uma sociedade civil forte para assegurar uma forma de accountability baseada no escrutínio público. Grupos voluntários, os meios de comunicação e os cidadãos ativos monitoram as instituições e as decisões para assegurar que elas sejam justas e inclusivas e, assim, para conferir ou recusar às organizações a credibilidade requerida para participar efetivamente dos processos de tomada de decisões.

O surgimento da governança tem sido acompanhada, portanto, de conceitos de accountability que enfatizam o desempenho mais que os procedimentos. A accountability de desempenho identifica a legitimidade primariamente com a satisfação dos dirigentes com os resultados, desviando- 
se desse modo dos problema que as novas teorias da governança associaram à accountability procedimental. Se o Estado é julgado por seu desempenho ou pelos resultados, há menor necessidade de aferrar-se à mística distinção entre os domínios administrativo e político. Além disso, a accountability de desempenho torna menos importante que as ações dos agentes ou dos subordinados sejam diretamente supervisionadas e julgadas pelo diretor.

Uma forma de conceber a accountability de desempenho é em termos de quase-mercados. Os cidadãos atuam como consumidores e expressam sua satisfação ao comprarem ou selecionarem serviços fornecidos por uma agência em vez de por outra. Ainda assim, as agências públicas com freqüência não têm os mecanismos de preço, de níveis de lucro e de orçamentos duros que poderiam fazer do mercado um indicador da satisfação do consumidor. Desse modo, uma outra forma de conceber a accountability de desempenho é em termos de medidas de resultados. Metas, benchmarks ${ }^{8}$ e outros padrões e indicadores fornecem uma base para monitorar-se e auditar-se o desempenho das agências públicas. Finalmente, a accountability de desempenho poderia ser incluída em trocas horizontais entre um sistema de atores; cada ator poria em questão o desempenho de outro.

É importante enfatizar que essas respostas aos problemas da governança democrática - as respostas dos cientistas sociais inspiradas pelos conceitos econômico e sociológico de racionalidade - não são somente acadêmicas; elas informam muito das políticas públicas. Assim como os atores políticos realizaram duas ondas de reformas do setor público que se basearam em versões formais e populares das teorias das Ciências Sociais, eles responderam a questões democráticas vinculadas às reformas aferrando-se às instituições representativas complementadas pelas instituições não-majoritárias, pela inclusão social e pela accountabilities de desempenho e horizontal.

\footnotetext{
8 A expressão "benchmark" é de difícil tradução; ela exprime o processo de comparação das práticas adotadas por várias organizações que satisfazem de maneiras diferentes as mesmas necessidades ou que produzem os mesmos bens; não é tanto a simples comparação o que interessa, mas a identificação (para posterior adoção) das "melhores práticas" (N. T.).
}

O exemplo dos governos central e local no Reino Unido exibe aderência contínua à imagem representativa da democracia, à disposição de conferir poder a instituições não-majoritárias e a reformas do setor público ativamente direcionadas para usar os mercados e as redes para favorecer a legitimidade. De início, as extensas reformas constitucionais dos últimos 15 anos sugerem que a idéia dominante de democracia permanece ligada às instituições representativas. Sucessivos governos perseguiram a visão liberal de governos territoriais em vários níveis e experimentos eleitorais mais ou menos até a exclusão de formas alternativas de pluralismo e de participação. Assembléias e eleições representativas mantêm-se como os focos das reformas. A devolução de poderes à Escócia e ao País de Gales consistiu largamente na criação de novos parlamentos em Edimburgo e em Cardiff. A desafortunada reforma das regiões inglesas tratava da criação de novas legislaturas territorialmente baseadas. Também em Westminster as reformas concentraram-se no parlamento, especialmente na Câmara dos Lordes ${ }^{9}$. Um outro aspecto das novas assembléias é a introdução de diversos sistemas eleitorais, mas isso de maneira bastante óbvia permanece firmemente nos quadros da democracia representativa.

O New Labour, embora inadvertidamente, ecoou a lógica das instituições não-majoritárias em seu primeiro gesto dramático - a concessão de independência ao Banco da Inglaterra ${ }^{10}$. Uma lógica similar aparece em suas reformas judiciais: o governo respondeu aos dilemas de eficiência e confiança promovendo a judicialização. Ele voltou-se para os juízes como especialistas que podem fornecer proteção eficiente aos direitos humanos e ao bem-estar social, na esperança de que os juízes criariam uma confiança generalizada nesse novo padrão de governo, desse modo conferindo ao Estado maior legitimidade. Novamente,

\footnotetext{
9 A expressão "Westminster" refere-se à sede do parlamento britânico; considerando que o Reino Unido é um país parlamentarista, por metonímia trata-se da sede do governo. Já a Câmara dos Lordes é a câmara alta do Reino Unido; ela é composta apenas pela nobreza (indicada pelo rei, ou rainha, da Inglaterra), pela participação na Igreja Anglicana ou por hereditariedade (N. T.).

10 É necessário indicar que o Banco da Inglaterra tem funções de banco central, controlando a taxa de juros e a política monetária do Reino Unido (N. T.).
} 
ao conferir poder às cortes com uma nova capacidade de rever a legislação doméstica - por exemplo, com a Lei de Direitos Humanos (de 1998) -, o governo efetivamente deu as boas-vindas às cortes no processo de tomada de decisões, de uma forma que, para o bem ou para o mal, reduziu o espectro de decisões que poderiam ser tomadas democraticamente. O poder Judiciário é uma instituição não-democrática cujo novo papel restringe (sem eliminar) o escopo de posteriores tomadas democráticas de decisões.

Embora a natureza não-escrita da constituição britânica borre a distinção entre os assuntos constitucionais e administrativos ainda mais que o usual, mantém-se uma clara distinção entre eles. A reforma do governo local pode ser primariamente constitucional ou administrativa. Os governos britânicos recentes flertaram com inovações democráticas, notadamente com prefeitos eleitos. Ainda assim, sua abordagem para o governo local concentrou-se quase inteiramente em reformas administrativas, incluindo o best value 11 , o "desempenho fiscal abrangente" 12 e os local area agreements ${ }^{13}$. Essas reformas administrativas às vezes refletem a idéia de que os mercados e as redes podem favorecer uma admirável nova democracia baseada na escolha ampliada e na inclusão social; mais freqüentemente, contudo, elas são tentativas de reafirmar o controle central e estabelecer padrões mínimos.

Os formuladores de políticas com freqüência respondem aos temas democráticos contemporâneos tentando complementar as instituições repre-

11 "Best value" é um programa do governo central britânico que orienta os administradores locais a buscarem o máximo de eficiência, eficácia e economia em suas gestões, buscando satisfazer as necessidades dos cidadãos dos locais que administram. A tradução literal da expressão é "melhor valor", mas como evidentemente ela perde o sentido na tradução, preferimos mantê-la no original (N. T.).

12 No original, "comprehensive performance assessment". Trata-se de um programa de auditoria fiscal britânico, em que os gastos dos governos locais são fiscalizados e avaliados de acordo com os parâmetros anteriormente indicados: eficácia, eficiência, economia, satisfação das necessidades dos cidadãos (N. T.).

13 Os "local area agreements" são planos trienais elaborados por conselhos municipais para orientar os gastos públicos nos governos locais britânicos. Literalmente a expressão significa "acordos de áreas locais", mas também neste caso a tradução perde o sentido original (N. T.). sentativas com um conhecimento técnico baseado em novas teorias modernistas da governança. É útil distinguir dois tipos de conhecimento técnico. Um primeiro baseia-se no conceito econômico de racionalidade encontrado na economia neoclássica e na teoria da escolha racional. Ele inspira uma erosão da democracia evidente em tentativas de restringir o escopo da tomada democrática de decisões a fim de lidar com as irracionalidades coletivas. Os assuntos públicos são transferidos para instituições não-majoritárias, incluindo bancos centrais independentes e juízes e cortes. Da mesma forma, decisões democráticas futuras são constrangidas por leis que requerem que a legislação, por exemplo, equilibre orçamentos ou respeito direitos jurídicos. Um segundo tipo de conhecimento técnico baseia-se no conceito sociológico de racionalidade encontrado no institucionalismo e em formas semelhantes de Ciência Social. Ele inspira um repensar da democracia que é evidente em novas ênfases na accountability horizontal e na inclusão social. As hierarquias burocráticas cedem espaço para redes joined-up. A segurança pública, a educação e outros serviços públicos crescentemente são baseados em parcerias que incluem organizações do setor privado e grupos comunitários.

Hoje, os formuladores de políticas regularmente evocam um admirável mundo novo de descentralização, envolvimento público e cessão de poder [empowerment]. Seria tolice desprezar essas falas. Os formuladores de políticas podem genuinamente acreditar que os mercados e as redes podem e devem promover ideais democráti$\cos$. No entanto, sua fé com freqüência deriva pelo menos implicitamente de afirmações de especialistas segundo as quais mercados e redes inclusivos podem apoiar uma governança eficiente que é percebida como legítima. Como tal, há uma possível tensão nesse admirável mundo novo. A participação e o diálogo são meios para a governança eficiente e a legitimidade percebida ou são meios para promover valores democráticos? $\mathrm{O}$ que acontecerá se o objetivo de promover a governança efetiva e a legitimidade percebida entrar em conflito com o de estender a inclusão social e a participação política?

\section{CONCLUSÃO}

A nova governança substitui um tipo de modernismo por outro. Vão embora a narrativa burocrática, o conhecimento técnico neutro das pro- 
fissões e a accountability prodecimental; entram os mercados e as redes, a teoria da escolha racional e o institucionalismo de redes e a accountability de desempenho. As mudanças são dramáticas. Ainda assim, a nova governança, tanto como teoria quanto como prática, continua sendo parte de um modernismo que desde há tempos luta para o fim da compreensão que o século XIX tinha do Estado.

Quando historicizamos o modernismo - quando o mostramos como uma forma particular e contestável de conhecimento -, criamos a possibilidade de mover-nos além dele. A Tabela 3 ilustra essa possibilidade. Em vez das abordagens modernistas às racionalidades econômica e soci- ológica, poderíamos conceber a vida social em termos de formas mais contingentes de razão local. Em vez de mover-nos da accountability procedimental para a de desempenho, poderíamos encorajar a accountability procedimental, talvez a tornando menos relativa a decisões que já foram tomadas e mais relativa a cidadãos tornando pessoas fiscalizáveis durante os processos de tomadas de decisões. Em vez de apelar para a falácia do conhecimento técnico, poderíamos explorar a possibilidade de um envolvimento e de um controle mais diretos pelos cidadãos por meio da formação e da implementação de políticas públicas; poderíamos defender conceitos mais plurais e participativos de democracia.

\section{TABELA3-APÓS O MODERNISMO}

\begin{tabular}{|c|c|c|c|}
\hline ÂMBITO & \multicolumn{2}{|c|}{ MODERNISMO } & APÓS O MODERNISMO \\
\hline $\begin{array}{l}\text { Conceito de } \\
\text { racionalidade }\end{array}$ & Econômico & Sociológico & Local \\
\hline $\begin{array}{l}\text { Teoria da Ciência } \\
\text { Social }\end{array}$ & Escolha racional & Institutionalismo & Teoria interpretativa \\
\hline Cidadania & Consumista & Comunitária & Pluralista \\
\hline Teoria democrática & Representativa & Representativa & Participativa \\
\hline $\begin{array}{l}\text { Elaboração de políticas } \\
\text { públicas }\end{array}$ & $\begin{array}{l}\text { Especialistas } \\
\text { (mercados) }\end{array}$ & Especialistas (redes) & Dialógica \\
\hline
\end{tabular}

FONTE: 0 autor.

Mark Bevir (mbevir@berkeley.edu) é Doutor em Teoria Política pela Universidade de Oxford (Inglaterra) e Professor do Departamento de Ciência Política na Universidade da Califórnia (Estados Unidos), campus de Berkeley.

\section{REFERÊNCIA BIBLIOGRÁFICA}

BEVIR, M. 2010. Democratic Governance.

Princeton: Princeton University. 